\title{
An objective determination of optimal site locations for detecting expected trends in upper-air temperature and total column ozone
}

\author{
K. Kreher ${ }^{1,2}$, G. E. Bodeker ${ }^{1}$, and M. Sigmond ${ }^{3}$ \\ ${ }^{1}$ Bodeker Scientific, Alexandra, New Zealand \\ ${ }^{2}$ BK Scientific, Mainz, Germany \\ ${ }^{3}$ Canadian Centre for Modelling and Analysis, Victoria, BC, Canada \\ Correspondence to: K. Kreher (karin@bodekerscientific.com)
}

Received: 27 October 2014 - Published in Atmos. Chem. Phys. Discuss.: 19 January 2015

Revised: 29 May 2015 - Accepted: 1 June 2015 - Published: 14 July 2015

\begin{abstract}
Detection of climate change requires a network of stable ground-based long-term measurements. Building upon earlier work, we first explore requirements of such measurements (such as maximum random uncertainty and sampling frequency) to ensure a minimum random uncertainty in monthly mean temperatures and to ensure effective detection of trends. In agreement with previous work we find that only for individual measurement random uncertainties $>0.2 \mathrm{~K}$ does the measurement random uncertainty start to contribute significantly to the random uncertainty in the monthly mean. For trend analysis, we find that the quality of the trend determination is only compromised when the measurement random uncertainty exceeds $2 \mathrm{~K}$ and measurements are made just once or twice a month.

In the second part of the study we provide guidance on how to most effectively design a measurement network. To this end we developed a method to objectively identify the optimal location of sites for detecting projected trends in upper-air temperatures and total column ozone in the shortest possible time. This is done by first estimating the spatial distribution of the minimum length of time during which measurements have to be made in order to detect projected trends in temperature and ozone. This quantity is calculated from the unforced variance in the signal and the degree of autocorrelation, both estimated from historical data sets and assumed not to change in the future, and the projected trends as estimated from chemistry-climate models. The optimal site locations are then selected by an iterative procedure based on the minimum time required to detect a trend and a minimal distance between different measurement sites. While the optimal sites identified here result from our use of only one of
\end{abstract}

a wide range of objective strategies, these results provide additional incentives for initiating measurement programmes at these sites or, if already in operation, to continue to be supported.

\section{Introduction}

Stratospheric temperatures represent the first-order connection between natural and anthropogenically driven changes in radiative forcing and changes in other climate variables at the Earth's surface. There is, therefore, a strong interest in detecting upper-air temperature trends as efficiently and reliably as possible. The vertical structure of temperature trends also provides important information for climate change attribution since increases in atmospheric long-lived greenhouse gas $(\mathrm{GHG})$ concentrations warm the troposphere but cool the stratosphere. Ozone also acts as a GHG and absorbs UV radiation in the stratosphere such that changes in ozone concentration also change the temperature structure of the atmosphere. Thus, dependable long-term measurements of temperature and ozone are essential for climate change detection and attribution studies.

Historical observations present challenges for estimating trends since measurement uncertainties can be large. A number of papers (e.g. Free et al., 2002; Wang et al., 2012, and references therein) point to the inherent, and partly irreparable, problems that arise from complicated merging of data sets of changing or unknown quality and different measurement approaches. Homogenisation of merged data sets cannot eliminate the respective uncertainty in derived trends. 
Although satellite instruments are capable of measuring the vertical distribution of temperature and ozone globally, the resultant measurement series are often deficient for trend detection for the following reasons: (1) the calibration of satellites, once in orbit, is a challenging task and slight differences in instrumental design, satellite and satellite-operation design, and retrieval algorithms impose severe difficulties on constructing homogeneous time series (Thompson et al., 2012); (2) individual satellites often measure over periods that are too short to detect trends, and may stop operating unexpectedly, preventing appropriate continuity or overlap in observations; and (3) the vertical and horizontal resolution of satellite measurements may be too coarse to allow for appropriate interpretation and attribution of observed changes.

Stable ground-based long-term temperature and ozone measurements at selected sites, adhering to stringent measurement standards and traceability protocols (e.g. Immler et al., 2010), facilitate the calibration of individual satellite instruments (e.g. Tobin et al., 2006; Balis et al., 2007; Adams et al., 2014) and support the merging of data sets from different satellites with the goal of creating reliable long-term climate data records (e.g. Tummon et al., 2015, and references therein). Such high-quality temperature and ozone time series can also support bridging any gaps that may emerge in satellite data records. With unexpected termination of satellite operations, as well as the ongoing change in satellite technology, bridging gaps becomes critical to creating a continuous monitoring system for the global atmosphere.

More importantly though, these data sets could allow trend analysis in their own right. A first requirement would be that measurements are performed with sufficiently low random uncertainty and at a sufficiently high sampling rate. The minimum requirements have been previously explored by Seidel and Free (2006). They found that observations with an uncertainty of $\leq 0.5 \mathrm{~K}$, made at least twice daily, at least once every 2 or 3 days, were sufficient to ensure accurate monthly climate statistics (specifically, monthly mean temperature and standard variation), i.e. only $\sim 5 \%$ of monthly statistics will be significantly different from those based on four observations per day.

A second requirement for the measurement network to provide a global picture of the trends is that the observing sites are strategically placed and sample a sufficiently diverse range of regimes. Most of the current measurement sites, however, are located close to populated areas for ease of access and for historical reason. With approximately $90 \%$ of the global population living in the Northern Hemisphere, measurement sites favour the Northern Hemisphere. As a result, such a distribution of sites is unlikely to be representative of the global climate. An example for this is the distribution of the initial 15 GRUAN (GCOS Reference UpperAir Network) sites considered at the time of this analysis, which are predominantly located at Northern Hemisphere mid-latitudes (see blue dots in Fig. 1). Hence, the need exists to provide an objective approach to determine the optimal

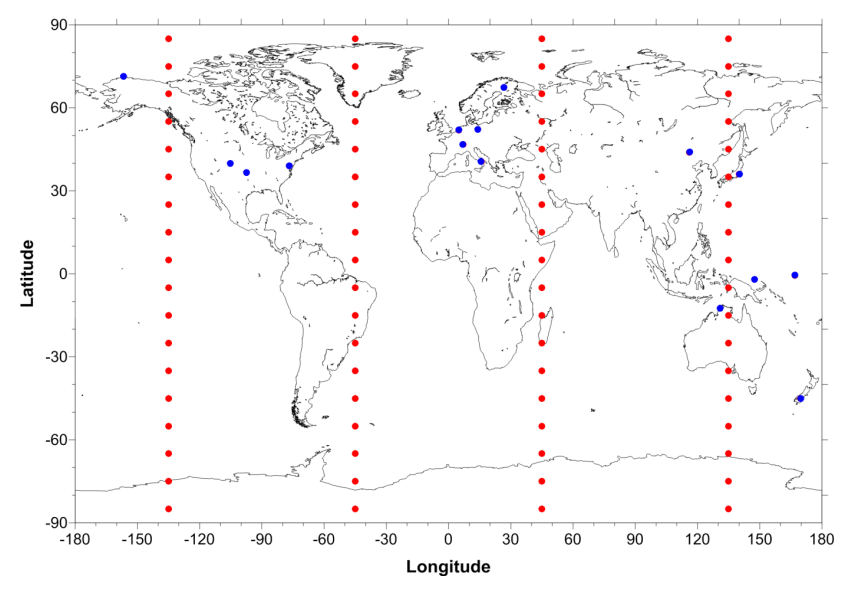

Figure 1. Map of the 87 locations used for the data analysis; 15 of the locations are the initial GRUAN sites (blue dots) and the other 72 of the locations (red dots) are positioned in $90^{\circ}$ longitude zones and $10^{\circ}$ latitude zones as shown on the map.

location of sites. To address this need, we describe one objective approach for locating sites for early temperature and ozone trend detection.

In the first part of this study (Sect. 2), we expand the analysis of Seidel and Free (2006) and examine the effects of the individual measurement random uncertainty (hereafter simply referred to as the "measurement uncertainty" to distinguish from systematic biases) and sampling strategy on the robustness of upper-air temperature trend detection. In the second part, we address the need for an objective approach for a site selection process, with the description and outcomes of the site selection process being described in Sect. 3 for temperature and in Sect. 4 for ozone.

\section{Sampling and trend detection using temperature profiles}

The two key questions addressed in this section are, what individual measurement uncertainty and measurement frequency is needed to achieve a certain uncertainty in monthly mean temperature, and what are the effects of the individual measurement uncertainty and sampling strategy on the ability to detect upper-air temperature trends?

The temperature profile data used within this study are 6-hourly data from the Climate Forecast System Reanalysis (CFSR; Saha et al., 2010) produced by the National Centers for Environmental Prediction (NCEP). Seidel and Free (2006), using the reanalysis of the climate of the past half century (Kistler et al., 2001) as a model of temperature variations over the next half century, tested various data collection protocols to develop recommendations for observing system requirements to monitor upper-air (here we define "upper air" as the free troposphere and above) temperature trends. The analysis of Seidel and Free (2006) focussed on 


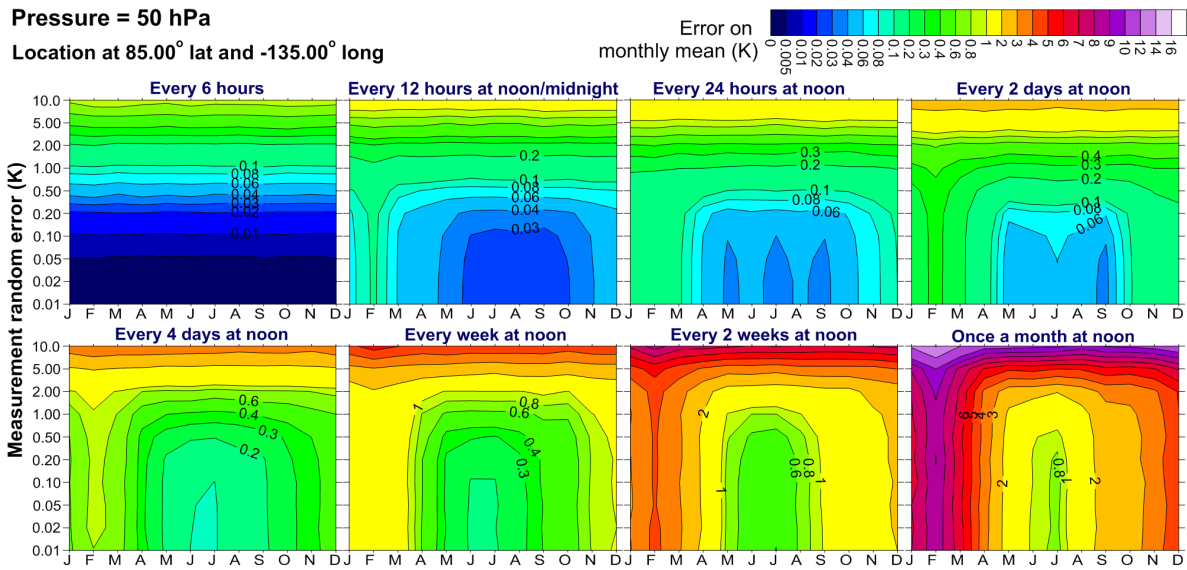

Figure 2. The uncertainty in the monthly mean temperatures at $50 \mathrm{hPa}, 85^{\circ} \mathrm{N}, 135^{\circ} \mathrm{W}$, for a range of sampling frequencies, as a function of the random uncertainty in each instantaneous measurement.

estimating monthly average temperature and its standard deviation, as well as multi-decadal trends in monthly temperatures at specific locations, from the surface to $30 \mathrm{hPa}$. The analysis presented here repeats, in part, that of Seidel and Free (2006), but extends above $30 \mathrm{hPa}$ (the highest level analysed by Seidel and Free, 2006) using NCEP CFSR temperature data to extend the results to $1 \mathrm{hPa}$ and to add to some of their conclusions, especially with the goal in mind to provide site location recommendations.

\subsection{Effects of sampling on monthly mean uncertainty}

To corroborate the findings of Seidel and Free (2006), and to extend the analysis into the upper stratosphere, a similar approach has been followed here, where for a number of selected locations, the uncertainty in monthly mean temperatures is determined as a function of the uncertainty in each contributing instantaneous measurement, sampling frequency, season, and pressure. For this study, we have used 72 locations in $90^{\circ}$ longitude zones and $10^{\circ}$ latitude zones and added the 15 initial GRUAN sites, which results in a total of 87 locations, as shown in Fig. 1.

The analysis is based on sampling of NCEP CFSR temperature fields with a spatial resolution of $0.5^{\circ} \times 0.5^{\circ}$, assuming that sampling at the highest possible frequency (6hourly) produces the "true" monthly mean. Then, by simulating different sampling strategies, with different simulated uncertainties on each measurement, and doing this in a Monte Carlo framework, the standard deviation of the differences between the calculated monthly means and the true monthly means can be determined.

Figure 2 shows the uncertainty in the monthly mean temperature at $50 \mathrm{hPa}$ and at $85^{\circ} \mathrm{N}, 135^{\circ} \mathrm{W}$ as a function of season and as a function of the uncertainty in each individual measurement for a range of different sampling frequencies listed in Table 1. The location has been selected randomly as an example and Fig. 3 shows the same information for
Table 1. List of applied sampling frequencies.

Every $6 \mathrm{~h}$
Every $12 \mathrm{~h}$ at noon/midnight
Every $24 \mathrm{~h}$ at noon
Every 2 days at noon
Every 4 days at noon
Every week at noon
Every 2 weeks at noon
Once a month at noon

a second randomly selected location $\left(35^{\circ} \mathrm{S}, 45^{\circ} \mathrm{E}\right)$. The top left panel in both Figs. 2 and 3 shows the uncertainty in the monthly mean for 6-hourly sampling throughout the month. There is no contribution to the uncertainty in the monthly mean from sampling because the same 6-hourly sampling is used to derive the "true" monthly mean. Therefore, the uncertainty in the monthly mean is about an order of magnitude smaller than the uncertainty in each instantaneous measurement, which is to be expected when averaging $\sim 120$ measurements through the month i.e. $1 / \sqrt{ } 120 \approx 0.1$. As can be seen clearly, the seasonal influence is minimal.

Note that this is the uncertainty in the monthly means, neglecting any systematic errors (offsets) as these are less important for trend analysis - so while sampling every $24 \mathrm{~h}$ at noon would produce monthly mean temperatures very different to what would be achieved when sampling every $24 \mathrm{~h}$ at midnight, the standard deviation of the differences between the calculated monthly mean and the true monthly mean (rather than the absolute value) is what is assessed. The uncertainty in the monthly mean now shows a clear seasonal cycle for 12-hourly sampling, or coarser, since the temperatures show a higher degree of variability in the winter months at this location and level. At this pressure level $(50 \mathrm{hPa})$, reductions in measurement uncertainty below $0.2 \mathrm{~K}$ have little effect on the uncertainty in the monthly mean because it 


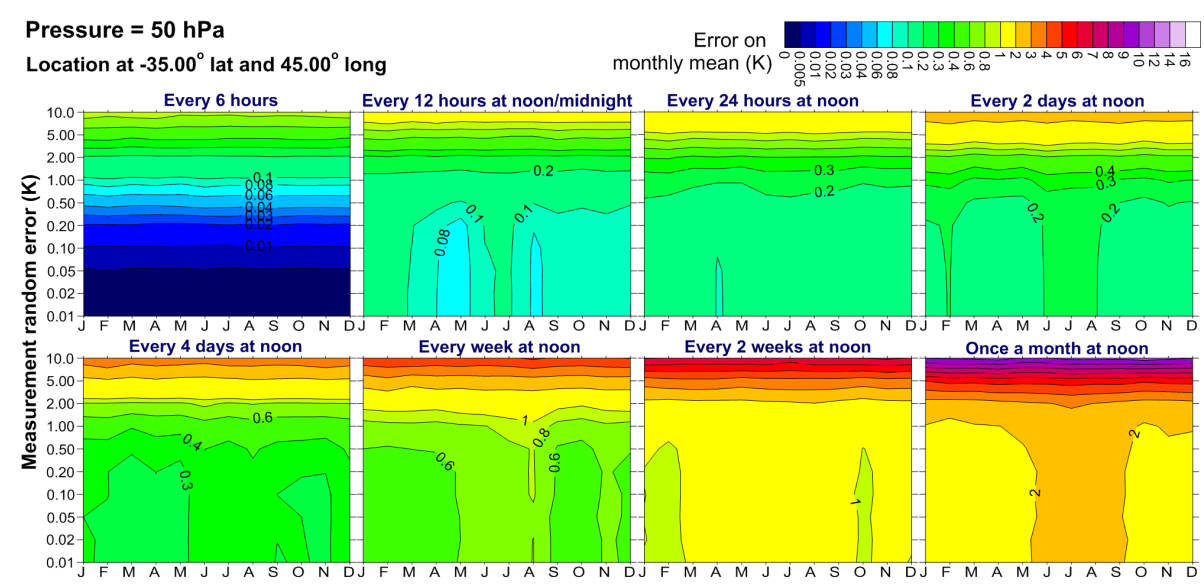

Figure 3. The uncertainty in the monthly mean temperatures at $50 \mathrm{hPa}, 35^{\circ} \mathrm{S}, 45^{\circ} \mathrm{E}$, for a range of sampling frequencies, as a function of the random uncertainty in each instantaneous measurement.

is the uncertainty resulting from incomplete sampling that dominates. It is only for a measurement uncertainty greater than $0.2 \mathrm{~K}$ that the measurement uncertainty begins to make an appreciable contribution to the uncertainty in the monthly mean. This $0.2 \mathrm{~K}$ threshold does not only apply to the two locations displayed in Figs. 2 and 3 - it is also valid for the other locations at $50 \mathrm{hPa}$ as well as most other sites at $500 \mathrm{hPa}$ (not shown here). The $0.2 \mathrm{~K}$ threshold also supports the GRUAN target of less than $0.2 \mathrm{~K}$ uncertainty for instantaneous stratospheric temperature measurements (Immler et al., 2010). The permissible measurement uncertainty varies with pressure and season.

The permissible uncertainty in individual temperature measurements required to avoid increasing the uncertainty in the monthly means by more than $10 \%$ above what would be achieved when sampling with $0.01 \mathrm{~K}$ uncertainty is shown in Fig. 4. Results from all the 87 locations selected for this analysis and for all months were averaged to produce this figure, with the individual curves showing the permissible uncertainty for each of the seven sampling frequencies.

When sampling every $12 \mathrm{~h}$, at noon/midnight (solid blue curve), in the upper stratosphere, measuring with $0.5 \mathrm{~K}$ uncertainty is sufficient to avoid affecting the uncertainty in the monthly means by more than $10 \%$; this reduces to $0.25 \mathrm{~K}$ at $\sim 20 \mathrm{hPa}$ and to $0.15 \mathrm{~K}$ in the free troposphere. If the frequency of sampling decreases, the sampling uncertainty comes to dominate, resulting in less stringent requirements on the uncertainty in each individual measurement. For example, for operational radiosonde sites making twice daily temperature profile measurements, there is something to be gained by reducing the uncertainty in each measurement to $0.2 \mathrm{~K}$ or less since this minimises the uncertainty in the resultant monthly means, thereby allowing for more robust estimates of upper-air temperature trends. For sites sampling only once per week, or less frequently (red, cyan and dark green curves in Fig. 4), a measurement uncertainty of $0.5 \mathrm{~K}$

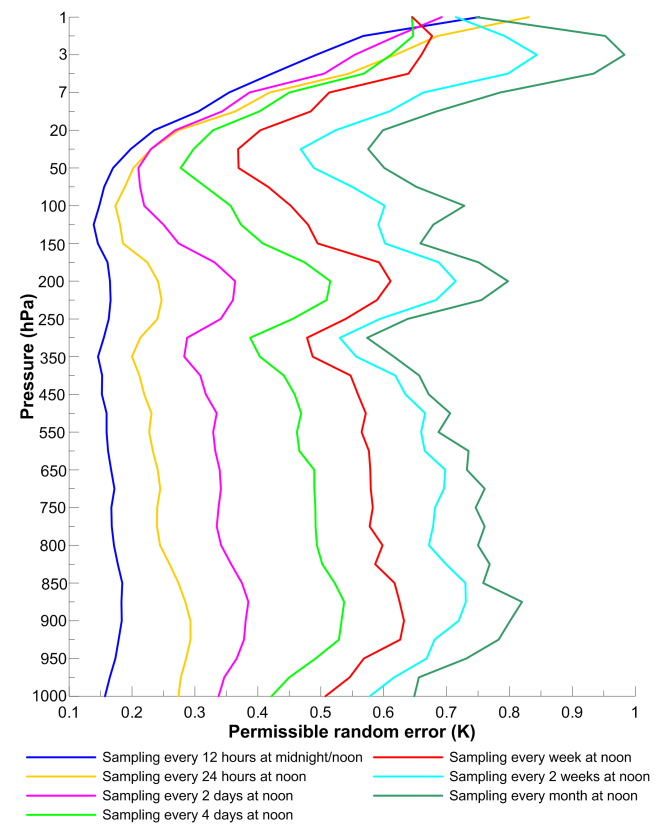

Figure 4. The permissible uncertainty in temperature measurements for a range of sampling frequencies required to avoid more than $10 \%$ increase in the uncertainty in the monthly means compared to the monthly mean uncertainty that would result from sampling with $0.01 \mathrm{~K}$ uncertainty. Results from all 87 sites selected for this analysis and for all months were averaged to produce this figure.

is sufficient to ensure that there is no additional increase in the random uncertainty in the resultant monthly means. Of course, with such infrequent sampling the monthly means will have greater uncertainties than with more frequent sampling. 


\subsection{Sampling strategies, measurement uncertainty, and trend detection}

The effects of individual measurement uncertainty and sampling strategy on the ability to detect upper-air temperature trends have also been investigated using the NCEP CFSR reanalyses temperature profiles. Temperature trends were calculated at each of the 37 pressure levels, for each of the 87 locations, using a state-of-the-art regression model (Bodeker et al., 1998).

This method was applied to each of the monthly mean time series, as generated above, based on different assumptions about the uncertainty in each of the individual temperature measurements, and the eight different sampling frequencies (see Table 1). A Monte Carlo bootstrap approach was used to estimate the uncertainty in the derived trends. In each case, 1000 statistically identical time series were generated by randomly sampling the initial regression model residuals and adding these residuals to the sum of the regression model basis function contributions, i.e. the forced part of the signal attributable to the different basis functions included in the regression model. In this case "statistically identical" refers to the 1000 time series that have the same underlying trend and forced variability but different structure of unforced variability. These 1000 time series are then also passed through the regression model to obtain 1000 trend values which are used to create a histogram of trends.

Two examples of the effects of (1) uncertainty in individual measurements and (2) sampling frequency on the quantification of temperature trends, calculated over the time period of 1979-2010, are displayed in Fig. 5. The graph shows that, at this location and pressure, the quality of trend detection is only significantly degraded with a sampling frequency of less than once weekly and with a measurement uncertainty $\geq 2 \mathrm{~K}$. At $50 \mathrm{hPa}$ and $39.95^{\circ} \mathrm{N}, 105.2^{\circ} \mathrm{W}$ (lower panel of Fig. 5), temperature trends of $\sim-0.032 \mathrm{Kdecade}^{-1}$ are statistically highly significant in that none of the 1000 Monte Carlo simulations produced positive trends, and are robust against almost all combinations of measurement uncertainty and sampling frequency. As in the previous example, it is only when the measurement uncertainty exceeds $2 \mathrm{~K}$, and measurements are made only once or twice per month, that the robustness of the trend determination is compromised.

\section{Site selection for temperature trend detection}

In this section, we address the following question: which of the existing sites engaged in upper-air temperature measurements are best located to detect expected future trends in upper-air temperatures within the shortest time possible? To do so, we explore and discuss one objective method (without claiming that it is the best or only method) for selecting the optimal locations for detecting projected 21 st century tem-

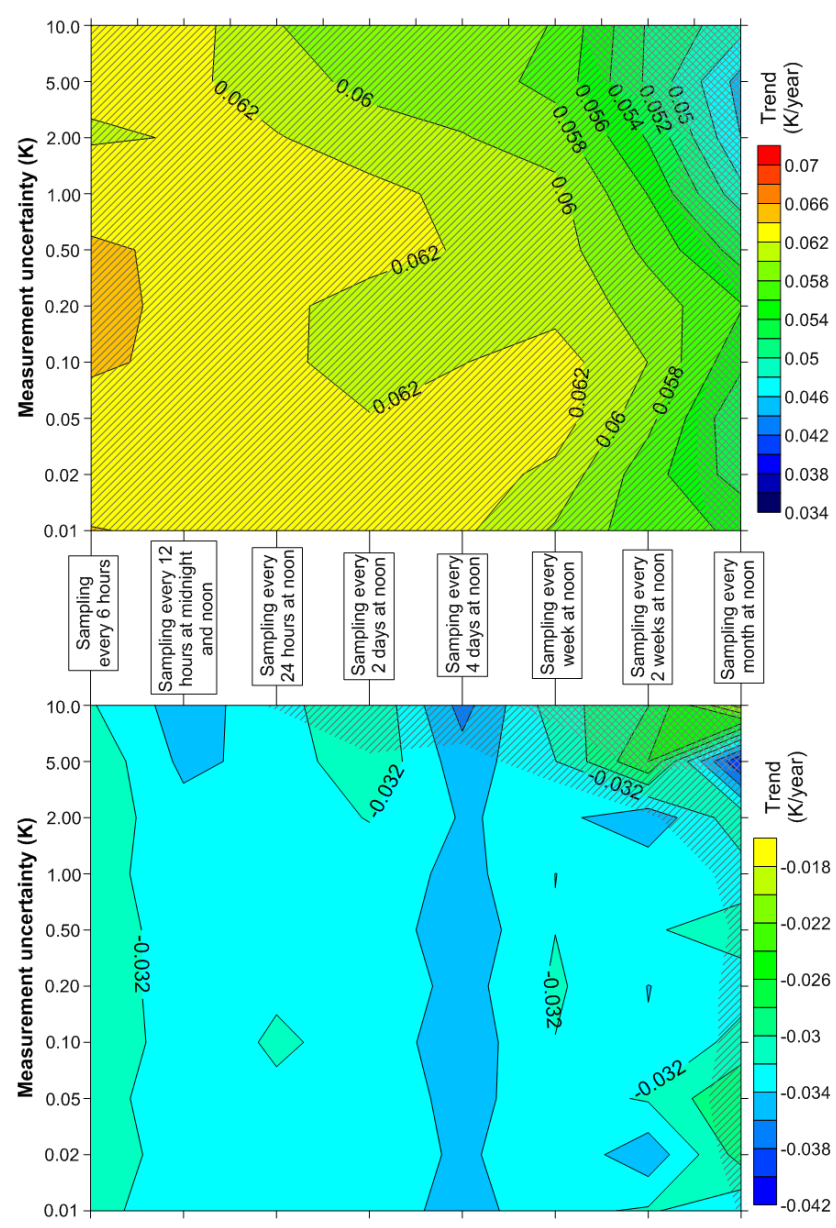

Figure 5. Upper panel: annual mean trends at $1 \mathrm{hPa}, 85^{\circ} \mathrm{N}, 135^{\circ} \mathrm{W}$, as a function of individual measurement uncertainty used to calculate the monthly means used as input to the regression analysis, and sampling frequency. Regions with single hatching show where trends are statistically significantly different from zero at between $1 \sigma$ and $2 \sigma$. Regions with double hatching show where the trend is not statistically significantly different from zero at $1 \sigma$. Lower panel: same analysis as upper panel but for $39.95^{\circ} \mathrm{N}, 105.2^{\circ} \mathrm{W}$, at $50 \mathrm{hPa}$.

perature trends at approximately 5 and $17.5 \mathrm{~km}$ altitude in the shortest time possible.

To provide specific guidance based on the material presented in Sect. 2, we investigated the number of years it would take to detect projected trends in upper-air temperatures for specified sampling regimens (both in terms of frequency and measurement uncertainty). Figure 6 shows expected 21 st century trends in upper-air temperatures obtained by averaging trends from REF-B2 simulations made by 11 chemistry-climate models (CCMs) as part of the SPARC CCMVal-2 activity (e.g. Young et al., 2013). REFB2 is the so-called reference simulation and is a selfconsistent transient simulation from 1960 to 2100 (Eyring et al., 2010). In this simulation the surface time series of halocarbons are based on the adjusted A1 scenario from 


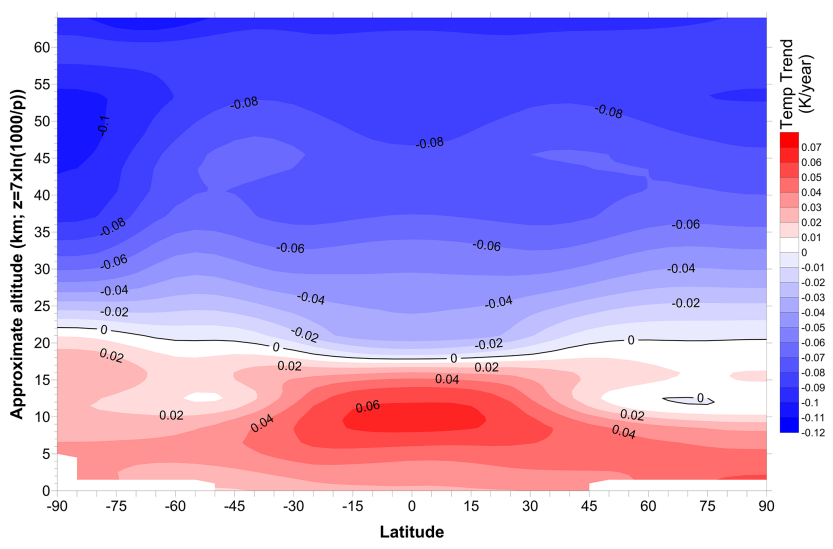

Figure 6. Projected trends in upper-air temperatures for 2000-2099 from 11 chemistry-climate models running the REF-B2 simulation from CCMVal-2.

WMO/UNEP (2007). The adjusted A1 halogen scenario includes the earlier phase out of hydrochlorofluorocarbons (HCFCs) that was agreed to by the parties to the Montreal Protocol in 2007 (Eyring et al., 2010). The long-lived GHG surface concentrations are taken from the SRES (Special Report on Emission Scenarios) GHG scenario A1B (IPCC, 2000).

The number of years of measurements required to detect a trend at the $95 \%$ confidence level with a probability of 0.9 can be approximated by (Whiteman et al., 2011)

$n^{*}=\left[\frac{3.3 \sigma_{N}}{\left|\omega_{0}\right|} \sqrt{\frac{1+\phi_{N}}{1-\phi_{N}}}\right]^{2 / 3}$,

where $\sigma_{N}$ is the standard deviation of the unforced variability in the time series, i.e. the standard deviation of the residuals after the application of the regression model (described in Sect. 2.2) to remove all known sources of variability, $\omega_{0}$ is the trend magnitude in $\mathrm{K}_{\text {year }}{ }^{-1}$ (see Fig. 6), and $\phi_{N}$ is the autocorrelation in the residuals (Tiao et al., 1990).

This equation implies that, after the calculated number of years, there is a $90 \%$ probability that a trend of the correct sign will have been detected, if we assume that detecting a trend means identifying a trend at the $95 \%$ confidence level. $\sigma_{N}$ and $\phi_{N}$ values for the 87 analysis locations at the 37 pressure levels were calculated from the NCEP CFSR time series for 120 different sampling regimens, i.e. 12 sampling strategies with varying sampling frequencies (see Table 1) and sampling times (noon or midnight) for 10 different measurement uncertainties ranging from 0.01 to $10 \mathrm{~K}$.

Examples of results for two sites are shown in Fig. 7 for when projected 21st century temperature trends shown in Fig. 6 are used in Eq. (1). The projected trend at $30 \mathrm{hPa}$ for $85^{\circ} \mathrm{N}$ (top plot of Fig. 7) is $-0.01612 \mathrm{~K} \mathrm{year}^{-1}$, and for $25^{\circ} \mathrm{N}$ it is $-0.03627 \mathrm{~K}$ year $^{-1}$ (bottom plot). Calculations were made for 3219 cases (87 locations and 37 pressure levels). Typically, only when the uncertainty in each mea-

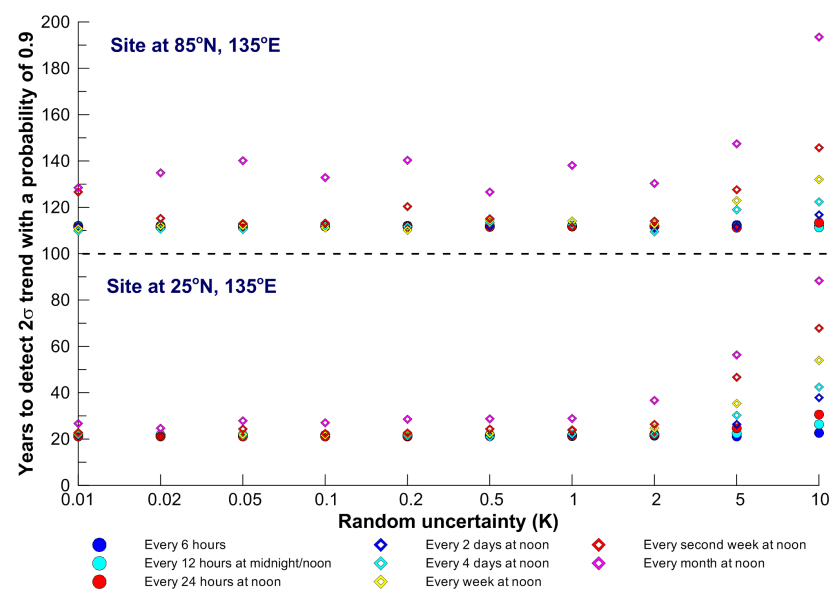

Figure 7. The time to detect projected 21 st century temperature trends at $30 \mathrm{hPa}$ at two sites for different sampling regimens that include a variety of measurement frequencies and measurement uncertainties. Trends were calculated using a standard least-squares regression model taking monthly means as input, calculated from individual measurements at the stated frequency and measurement uncertainty (indicated by the coloured circles and diamonds).

surement exceeds $2 \mathrm{~K}$ is the ability to detect trends significantly compromised, consistent with the findings presented in Sect. 2.2.

When comparing the results for the two sites displayed in Fig. 7, one in the tropics and one at high latitudes, it is clear that the uncertainty in each temperature measurement has little impact on the time required to detect the projected trend. Similarly, it is only for sampling regimens of every 4 days, or less often, that the sampling frequency affects the number of years required to detect the projected trend (see also Seidel and Free, 2006). The biggest effect on the time required to detect the projected trend stems from the natural variability (the noise) in the time series, the autocorrelation in the data and the magnitude of the expected trend. While for the site at $25^{\circ} \mathrm{N}$ the projected trend is expected to be detected within 30 years or less, for the site at $85^{\circ} \mathrm{N}$, the projected trend will likely not be detected within 100 years.

To further synthesise the results, three pressure levels, viz. 50,10 , and $1 \mathrm{hPa}$, were selected to investigate which measurement regimens, if any, allow for the detection of a temperature trend within 30 years, assuming an uncertainty in each measurement of $1 \mathrm{~K}$. It is apparent from the analysis (not shown here) that, in the upper stratosphere $(1 \mathrm{hPa})$, it is possible to detect temperature trends in the tropics $\left(30^{\circ} \mathrm{S}\right.$ to $30^{\circ} \mathrm{N}$ ) with almost any measurement programme - even one measurement per month would be sufficient to detect the trend within 30 years. Over the Arctic, however, no measurement regimen, no matter how frequently the measurements are made, and even if the measurements are made with very small uncertainty (at $0.01 \mathrm{~K}$ ), would detect the annual temperature trend within 30 years. In contrast to this, in the 
Antarctic, most measurement regimens (at $1 \mathrm{~K}$ uncertainty) would detect the trend within 30 years. Over the southern mid-latitudes, the trends would be detected at only one location within 30 years, whereas over northern mid-latitudes, trends may be detected at several locations.

At $10 \mathrm{hPa}$, the situation is similar to the $1 \mathrm{hPa}$ level, with tropical trends being detected more easily than extratropical ones, but the robustness now also extends to northern midlatitudes. The trend detection over the Antarctic is less robust. At $50 \mathrm{hPa}$, trends may be detectable at up to half of the locations within the tropics, whereas in the extratropical regions, no measurement regimen would lead to the detection of the expected temperature trends within 30 years.

This analysis was performed using annually averaged trends and it might well be that trends in some seasons are more likely to be detectable than in the annual mean, either because the trend is steeper in that season or because the variability in that season is smaller, or both. For the purposes of trend detection, analyses such as those summarised in Fig. 7 should be conducted for any proposed measurement site to define the required random uncertainty in the measurements, the measurement regimen, and the time it is likely to take to detect the expected trend in temperature. Sites should then be selected based on the magnitude of the expected trend, the natural variability, and the autocorrelation in the data as detailed in Eq. (1).

To identify such preferable sites where temperature trends could be identified sooner than elsewhere, an analysis based on Microwave Sounding Unit (MSU) and Advanced Microwave Sounding Unit (AMSU) temperature measurements, available from remote sensing systems (Mears and Wentz, 2008), was carried out. Figure 8 shows the results of this analysis for the merged MSU channel 2 and AMSU channel 5 temperatures. These are indicative of the middle troposphere with the weighting function peaking at $\sim 5 \mathrm{~km}$ altitude. The standard deviation of the residuals from the application of the regression model to monthly mean temperatures (Fig. 8a) and the first-order autocorrelation coefficient (Fig. 8b) are two of the quantities needed to calculate the number of years required to detect a prescribed temperature trend as detailed in Eq. (1).

The month-to-month variability in the data minimises in the tropics and maximises over high latitudes, particularly over the Canadian Arctic. This would suggest that the tropics would be ideally suited to long-term temperature trend detection in the middle troposphere. However, as shown in Fig. 8b, the autocorrelation in the temperature time series also maximises in the tropics. When the standard deviation on the monthly means and the calculated first-order autocorrelation are used together with a prescribed trend of $0.5 \mathrm{~K} \mathrm{decade}^{-1}$ in Eq. (1), the results shown in Fig. 8c are obtained. Large regions of the tropics and subtropics have temperature time series that would be amenable to detection of mid-troposphere temperature trends of $0.5 \mathrm{Kdecade}^{-1}$ within $\sim 10$ years. However, as seen in Fig. 6, temperature trends at $5 \mathrm{~km}$ are
Table 2. Proposed measurement sites for the detection of 21 st century temperature trends at the middle troposphere.

\begin{tabular}{llll}
\hline Site name & Latitude & Longitude & Observation network \\
\hline Annette Island & $55.0^{\circ} \mathrm{N}$ & $131.3^{\circ} \mathrm{E}$ & GUAN \\
La Coruna & $43.3^{\circ} \mathrm{N}$ & $8.5^{\circ} \mathrm{W}$ & GUAN, WOUDC \\
Kashi & $39.3^{\circ} \mathrm{N}$ & $75.6^{\circ} \mathrm{E}$ & GUAN \\
Kingston & $17.6^{\circ} \mathrm{N}$ & $76.5^{\circ} \mathrm{W}$ & GUAN \\
Guam & $13.3^{\circ} \mathrm{N}$ & $144.5^{\circ} \mathrm{E}$ & GUAN \\
Tromelin Island & $15.5^{\circ} \mathrm{S}$ & $54.3^{\circ} \mathrm{E}$ & GUAN \\
St. Helena & $15.6^{\circ} \mathrm{S}$ & $5.4^{\circ} \mathrm{W}$ & GUAN \\
Rarotonga & $21.1^{\circ} \mathrm{S}$ & $159.5^{\circ} \mathrm{W}$ & GUAN \\
Puerto Montt & $41.3^{\circ} \mathrm{S}$ & $73.1^{\circ} \mathrm{W}$ & GUAN \\
Dumont d'Urville & $66.7^{\circ} \mathrm{S}$ & $140.0^{\circ} \mathrm{E}$ & GUAN, NDACC \\
\hline
\end{tabular}

not $0.5 \mathrm{~K} \mathrm{decade}^{-1}$ everywhere. If we use the expected temperature trends at $5 \mathrm{~km}$ from Fig. 6 in Eq. (1), then the results displayed in Fig. 8d are obtained. This is the optimal figure to use for deciding where to locate measurement sites for detecting trends in mid-tropospheric temperatures.

One objective strategy (but certainly not the only strategy) is to select an existing site from the relevant global observation networks closest to the minimum value shown in Fig. 8d. For the purposes of this study, only sites from GRUAN and GUAN (GCOS Upper-Air Network; GCOS73, 2002, http://www.wmo.int/pages/prog/gcos/documents/ GUAN_map_2014.pdf) were considered for this selection. The site closest to the minimum value was found to be the GUAN site at Guam. The next site with the next shortest time to detect expected mid-tropospheric temperature trends, which is at least $6000 \mathrm{~km}$ from Guam (since it is not necessary to have sites very close together), is the GUAN station on Tromelin Island. We then continue to look through the list of existing measurement sites, ordered by the number of years required to detect trends, selecting sites that are at least $6000 \mathrm{~km}$ away from the already selected sites. The resultant distribution of sites is shown in Fig. 8d and also listed in Table 2. Such a selection of sites would provide good global coverage with a preference for sites in regions where the time to detect expected trends in mid-troposphere temperatures is minimal.

Figure 9 shows the results of a similar analysis, but now using merged MSU channel 4 and AMSU channel 9 temperatures indicative of the lower stratosphere (weighting functions peaking at $\sim 17.5 \mathrm{~km}$ ). The approach described above is used for selecting the optimal measurement sites, now resulting in different sites including one site in the Arctic (Barrow), as well as one Antarctic site (Amundsen-Scott, South Pole), with less emphasis on tropical sites. The sites shown in Fig. 9 are also listed in Table 3.

Note that this is just one possible strategy for selecting sites for detecting expected long-term trends in midtroposphere and lower stratosphere temperatures. Clearly, different strategies would result in a different list of ideal sites and strategies need to be tailored to accommodate other 

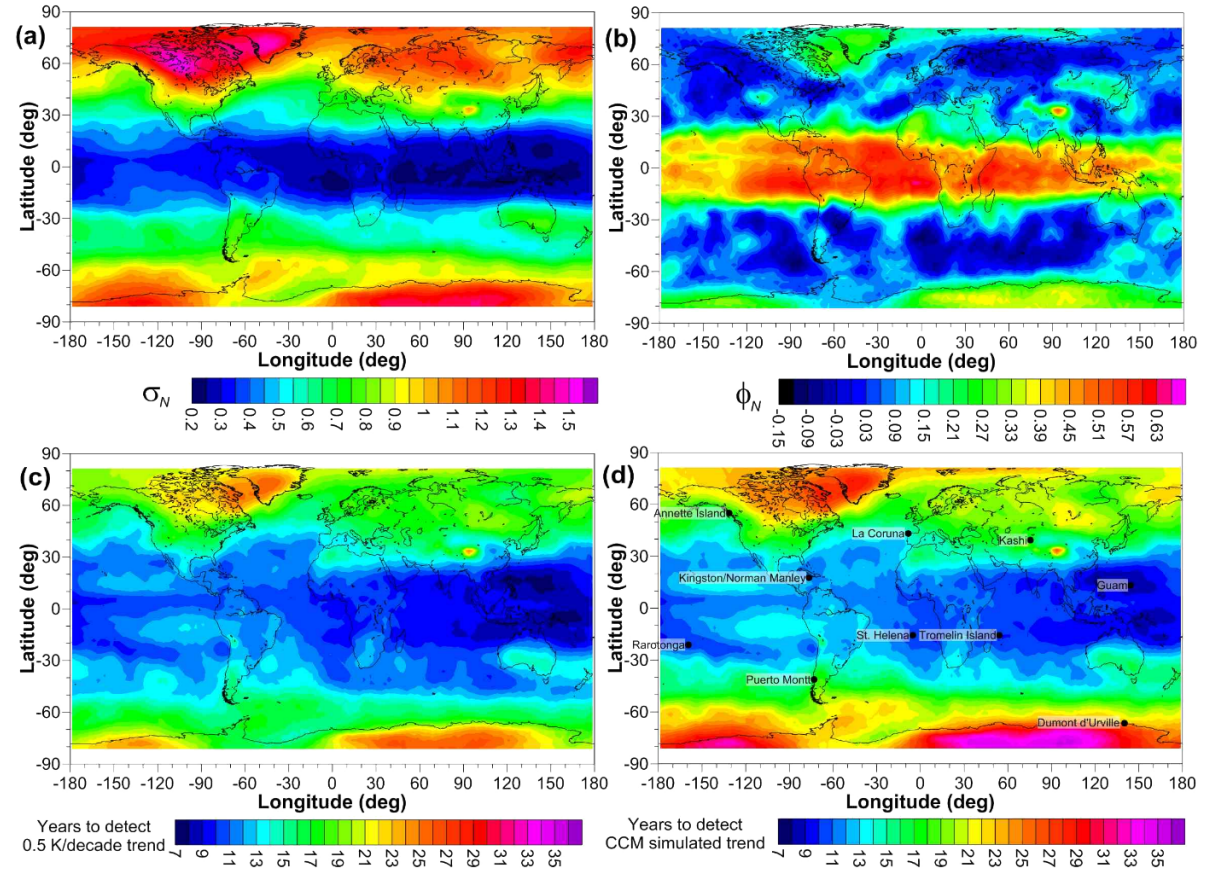

Figure 8. Analyses of merged MSU channel 2 and AMSU channel 5 temperature data - 1978 to 2013. (a) Standard deviation of regression model residuals, (b) the first-order autocorrelation coefficient of the residuals, (c) the number of years required to detect a trend of $0.5 \mathrm{~K} \mathrm{decade}^{-1}$, and (d) the number of years required to detect the trend at $5 \mathrm{~km}$ altitude (close to where the MSU channel 2 and AMSU channel 5 weighting functions peak) as shown in Fig. 6. Only existing GUAN and GRUAN stations have been used as a basis to select the optimal sites for early trend detection shown here.

Table 3. Proposed measurement sites for the detection of 21 st century temperature trends at the lower stratosphere.

\begin{tabular}{llll}
\hline Site name & Latitude & Longitude & Observation network \\
\hline Barrow & $71.3^{\circ} \mathrm{N}$ & $156.6^{\circ} \mathrm{W}$ & GRUAN, ARM, GAW \\
Key West & $24.3^{\circ} \mathrm{N}$ & $81.5^{\circ} \mathrm{W}$ & GUAN \\
Asswan & $23.6^{\circ} \mathrm{N}$ & $32.5^{\circ} \mathrm{E}$ & GUAN \\
Chichijima & $27.1^{\circ} \mathrm{N}$ & $142.1^{\circ} \mathrm{E}$ & GUAN \\
Rapa & $27.4^{\circ} \mathrm{S}$ & $144.2^{\circ} \mathrm{W}$ & GUAN \\
Perth Airport & $31.6^{\circ} \mathrm{S}$ & $115.6^{\circ} \mathrm{E}$ & GUAN \\
Cape Town & $33.6^{\circ} \mathrm{S}$ & $18.4^{\circ} \mathrm{E}$ & GUAN \\
Ezeiza Aero & $34.5^{\circ} \mathrm{S}$ & $58.3^{\circ} \mathrm{W}$ & GUAN \\
South Pole & $90.0^{\circ} \mathrm{S}$ & 0.0 & GUAN, NDACC, GAW \\
\hline
\end{tabular}

factors such as cost, accessibility, and measurement capability. The purpose of this exercise is to show that generating fields, such as those shown in Figs. 8d and 9d, provide one objective method of selecting the optimal location of sites for detecting long-term temperature trends in different regions of the atmosphere within the shortest possible time.

\section{Site selection criteria for the detection of ozone trends}

As was done for upper-air temperature trends, we demonstrate a similar technique for objectively selecting optimal locations for detecting expected future trends in total column ozone. Expected ozone trends for different periods (see below) were obtained from $21 \mathrm{CCM}$ simulations of total column ozone changes over the 21st century under the CCMVal2 REF-B2 scenario. Except for one model (CMAM), sea-surface temperatures and sea-ice concentrations are prescribed from coupled ocean model simulations, either from simulations with the ocean coupled to the underlying general circulation model or from coupled ocean-atmosphere models used in the IPCC Fourth Assessment Report under the same GHG scenario. At each latitude and longitude, the median ozone trend value from the $21 \mathrm{CCM}$ simulations available was extracted and used as the indicative total column ozone trend.

Trends in total column ozone, unlike those in temperature, are not expected to be linear over the coming century over many regions of the globe. It is therefore less relevant to consider the time to detect expected 21 st century trends in total column ozone as an indicator of where total column ozone observing sites should be located. For example, in some region of the globe, such as the tropics, where ozone is ex- 

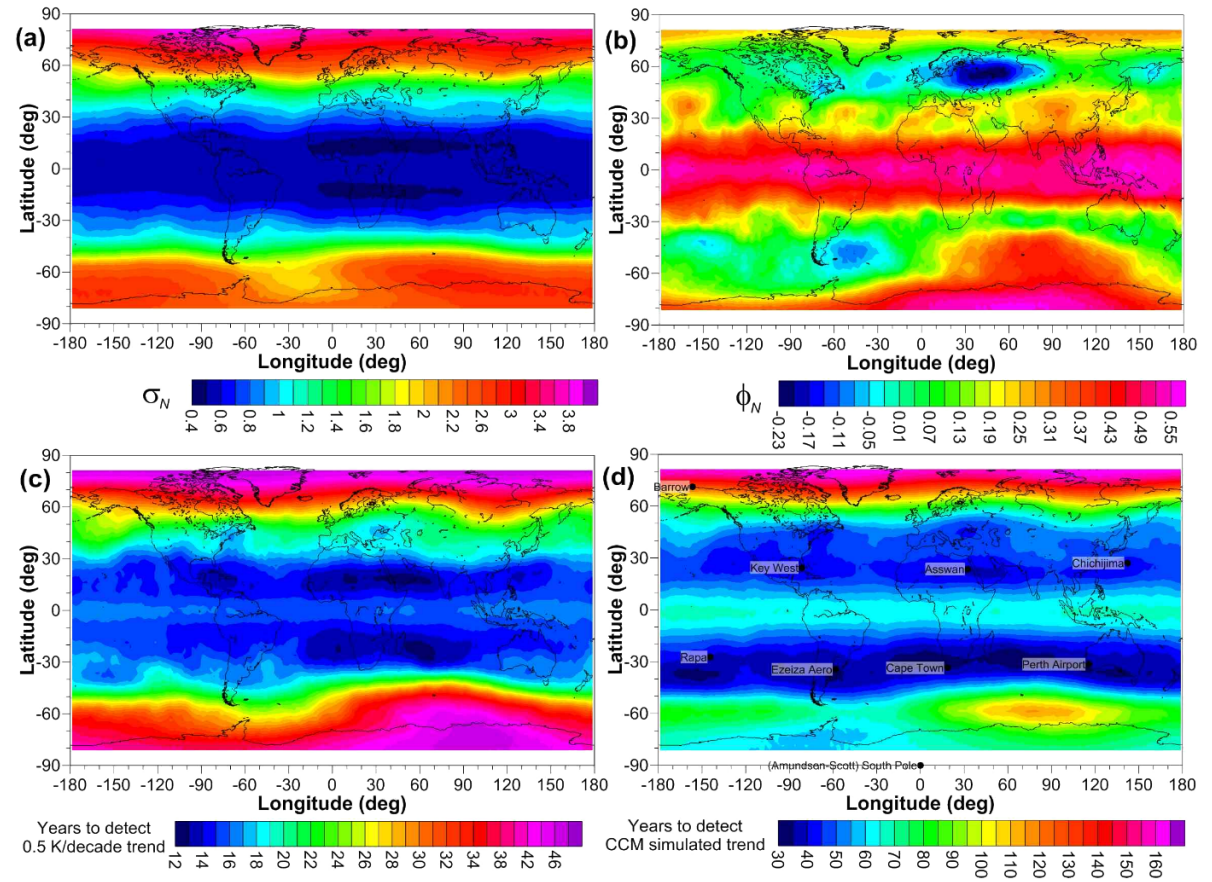

Figure 9. Analyses of merged MSU channel 4 and AMSU channel 9 temperature data - 1978 to 2013. (a) Standard deviation of regression model residuals, (b) the first-order autocorrelation coefficient of the residuals, (c) the number of years required to detect a trend of $0.5 \mathrm{~K} \mathrm{decade}^{-1}$, and (d) the number of years required to detect the trend at $17.5 \mathrm{~km}$ altitude (close to where the MSU channel 4 and AMSU channel 9 weighting functions peak) as shown in Fig. 6. Only existing GUAN and GRUAN stations have been used as a basis to select the optimal sites for early trend detection shown here.

pected to increase until the middle of the 21 st century and then to decrease thereafter, the time to detect the expected trend until 2100 may be significantly longer than the time to detect the trend until 2050. The approach taken is therefore to first conduct an analysis, similar to that for temperature, but considering expected trends in ozone from 2010 to 2020 and identifying which set of locations would be best suited for detecting those expected trends. The trend period is then extended by 1 year to consider trends from 2010 to 2021, and a second set of sites is identified. This is repeated until 20102050 , thereby creating 31 sets of optimal sites for detecting ozone trends. An example of the outcomes of this analysis for the 2010-2050 time period is shown in Fig. 10a.

Monthly mean total column ozone data obtained from the Bodeker Scientific total column ozone database ${ }^{1}$ spanning the period November 1978 to August 2012 were then analysed for their standard deviation and first-order autocorrelation, two of the quantities needed to calculate the number of years required to detect a prescribed total column ozone trend using Eq. (1). The model used to derive the residuals was similar to that used in Bodeker et al. (2001), which includes terms accounting for the mean annual cycle, the linear trend, the quasi-biennial oscillation (QBO), the El Niño-Southern Oscillation (ENSO), the solar cycle, and the El Chichón and

\footnotetext{
${ }^{1}$ http://www.bodekerscientific.com/data/total-column-ozone
}

Mt Pinatubo volcanic eruptions. The resultant standard deviation of the monthly means and the first-order autocorrelation coefficient are displayed in Fig. 10b and c. Month-tomonth variability in the data minimises in the tropics and maximises over high latitudes, particularly over Siberia. This would suggest that the tropics would be ideally suited to long-term total column ozone trend detection. However, as shown in Fig. 10c, the autocorrelation in the total column ozone also maximises in the tropics. The autocorrelation in ozone and other atmospheric trace gases is the result of the time and spatial scale of weather patterns as well as possible long-term forcing mechanisms (Tiao et al., 1990). Such autocorrelations have the effect of reducing the amount of information that would be available from the same number of independent measurements and generally increases the size of the measurement uncertainty.

When the standard deviation of the regression model residuals and the first-order autocorrelation are used together with the projected trends in total column ozone, the results shown in Fig. 10d are obtained. As can be seen clearly in Fig. 10, the magnitude of the autocorrelation in the total column ozone has a strong impact on the estimate of the number of years of measurements required to detect a trend based on Eq. (1). This agrees with previous work done by Tiao et al. (1990); they showed that a large positive autocorrelation in the monthly mean data (e.g. total column ozone) will have 

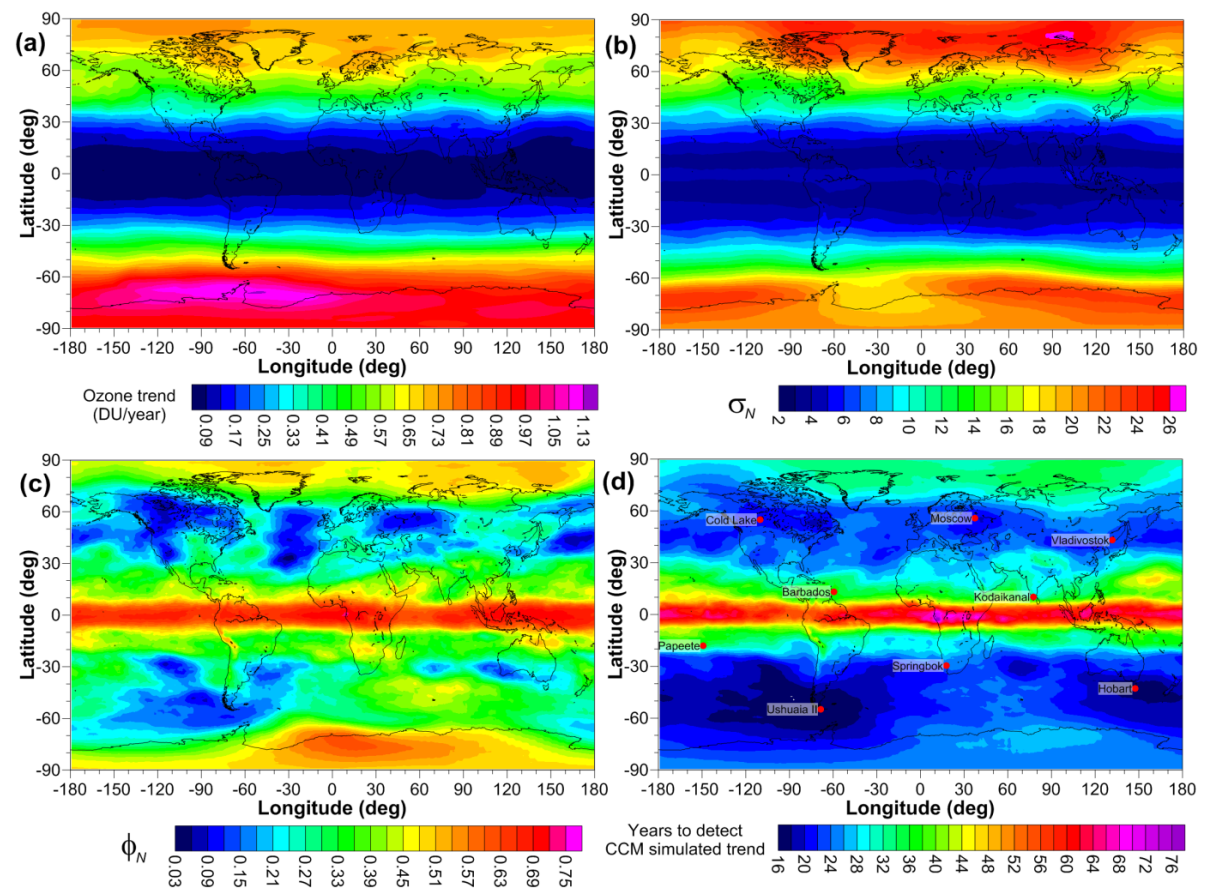

Figure 10. (a) Total column ozone trends in DU per year obtained from median values of trends calculated from 21 CCM projections of ozone over the period 2010 to 2050, (b) the standard deviation in regression model residuals in monthly mean total column ozone calculated from the Bodeker Scientific total column ozone database, (c) the first-order autocorrelation coefficient of the residuals, and (d) the number of years required to detect the expected total column ozone trends displayed in (a). Also shown in (d) are selected locations which are at least $6000 \mathrm{~km}$ apart but sample regions of short periods to detect expected trends.

a severe effect on the uncertainty in trend estimates and hence substantially increase the length of data records required to achieve the same degree of low uncertainty, compared to a situation where the data would be independent over time.

The distribution for the number of years required to detect the expected trends in total column ozone shown in Fig. 10d overall agrees with results from an earlier study by Weatherhead et al. (2000). Both studies show, for example, that the areas of high detectability are in the Southern Hemisphere around New Zealand/eastern Australia and southern South America and that locations close to the Equator require the longest time for trend detection. The study by Weatherhead et al. (2000) also shows that the detection of expected trends in most parts of the Northern Hemisphere will take longer than in the Southern Hemisphere (their Plate 5), which is also evident in our Fig. 10 but not as pronounced. It should be noted that Weatherhead et al. (2000) use a similar technique to calculate the expected number of years for the ozone trend detection but a different model (Goddard Space Flight Center two-dimensional chemical model) to predict the trends and a different ozone data set (Nimbus 7 TOMS data).

In analogy to the temperature trends, one objective strategy (but certainly not the only strategy) to use Fig. 10d to determine optimal locations for measurement sites is to select an existing site closest to the minimum value shown in
Fig. 10d. In this case only sites from WOUDC, SHADOZ and NDACC networks were considered.

The site closest to the minimum value was found to be the historical WOUDC site at Ushuaia (II). We now look for the next site with the shortest time to detect expected total column ozone trends that is at least $6000 \mathrm{~km}$ from Ushuaia. This is found to be Hobart. We then continue to look through the list of existing measurement sites, ordered by the number of years required to detect trends, selecting sites that are at least $6000 \mathrm{~km}$ away from sites already selected. The resultant distribution of sites is shown in Fig. 10d, and the nine sites are listed in Table 4. We expect that such a selection of sites would provide sufficient global coverage for trend detection with a preference for sites in regions where the time to detect expected total column ozone trends is as short as possible.

To provide a perspective on how these nine proposed sites, selected for trend detection in total column ozone from 2010 to 2050 , compare to the other 30 sets of sites, selected for each of the other trend periods (2010-2020 to 2010-2049), we have collated a list of all the sites selected for the 31 trend periods. Within this analysis, a total of 66 sites were selected with 23 of these sites being located in the Southern Hemisphere and Hobart being the overall most frequently selected site (23 times). We then ranked the sites accordingly to how frequently they were selected and in Table 5, we show the five most frequently selected sites for the Northern and 
Table 4. Proposed measurement sites for the detection of ozone trends from 2010 to 2050.

\begin{tabular}{llll}
\hline Site name & Latitude & Longitude & Observation network \\
\hline Cold Lake & $54.8^{\circ} \mathrm{N}$ & $110.1^{\circ} \mathrm{W}$ & Historical WOUDC \\
Moscow & $55.7^{\circ} \mathrm{N}$ & $37.5^{\circ} \mathrm{E}$ & Historical WOUDC \\
Vladivostok & $43.1^{\circ} \mathrm{N}$ & $131.9^{\circ} \mathrm{E}$ & Historical WOUDC \\
Barbados & $13.1^{\circ} \mathrm{N}$ & $59.5^{\circ} \mathrm{W}$ & Historical WOUDC \\
Kodaikanal & $10.2^{\circ} \mathrm{N}$ & $77.4^{\circ} \mathrm{E}$ & Historical WOUDC \\
Papeete & $18.0^{\circ} \mathrm{S}$ & $149.0^{\circ} \mathrm{W}$ & $\begin{array}{l}\text { Historical WOUDC } \\
\text { \& historical SHADOZ }\end{array}$ \\
& & & Historical WOUDC \\
Springbok & $29.7^{\circ} \mathrm{S}$ & $17.9^{\circ} \mathrm{E}$ & Historical WOUDC \\
Hobart & $42.9^{\circ} \mathrm{S}$ & $147.5^{\circ} \mathrm{E}$ & Historical WOUDC \\
Ushuaia II & $54.9^{\circ} \mathrm{S}$ & $68.4^{\circ} \mathrm{W}$ & Hal \\
\hline
\end{tabular}

Southern Hemisphere each. Three of the sites listed in Table 4 (Moscow, Papeete and Hobart) are also on the list of the 10 most often selected sites summarised in Table 5.

\section{Discussion and summary}

For a number of globally distributed locations (87 in total; see Fig. 1), the dependence of the uncertainty in monthly mean temperatures on individual measurement uncertainty, sampling frequency, season, and pressure was assessed using NCEP CFSR reanalyses. Our results show that the measurement uncertainty only starts to contribute significantly to the uncertainty in the monthly mean when individual temperature measurement uncertainties are greater than $0.2 \mathrm{~K}$. In practical terms, this means that for operational radiosonde stations which carry out temperature profile measurements twice daily, it is worthwhile to work to reduce the uncertainty in each measurement to $\leq 0.2 \mathrm{~K}$ since this minimises the uncertainty in the resultant monthly means, which should lead to more robust estimates of upper-air temperature trends. However, there is little to be gained by reducing the measurement uncertainty to much less than $0.2 \mathrm{~K}$. This conclusion supports the recommendations made by GRUAN.

With a reduction in sampling frequency, the sampling uncertainty starts to dominate, such that less rigorous criteria regarding the uncertainty requirements for each individual measurement are acceptable. For example, for sites where sampling is done only weekly or less frequently, measurement uncertainties of $0.5 \mathrm{~K}$ are sufficient to ensure that there is no additional increase in the random uncertainty in the resultant monthly means by more than $10 \%$ above what would be achieved when sampling with $0.01 \mathrm{~K}$ uncertainty. This concurs with the findings of Seidel and Free (2006), who found that if the individual measurement uncertainty is at least $0.5 \mathrm{~K}$, monthly means are accurate to within $\sim 0.05 \mathrm{~K}$, and standard deviations are accurate to within $10 \%$.
Table 5. The five most frequently selected Northern Hemisphere sites in the 31 sets of optimal sites followed by the five most frequently selected Southern Hemisphere sites.

\begin{tabular}{llll}
\hline Site name & Latitude & Longitude & Observation network \\
\hline Kyiv-Goloseyev & $50.3^{\circ} \mathrm{N}$ & $30.5^{\circ} \mathrm{E}$ & Current WOUDC \\
Sapporo & $43.0^{\circ} \mathrm{N}$ & $141.3^{\circ} \mathrm{E}$ & Current WOUDC, GUAN \\
Moscow & $55.7^{\circ} \mathrm{N}$ & $37.5^{\circ} \mathrm{E}$ & Historical WOUDC \\
Edmonton/Stony Pl. & $53.5^{\circ} \mathrm{N}$ & $114.1^{\circ} \mathrm{W}$ & Historical WOUDC \\
Coolidge Field & $17.3^{\circ} \mathrm{N}$ & $61.8^{\circ} \mathrm{W}$ & Historical WOUDC \\
Hobart & $42.9^{\circ} \mathrm{S}$ & $147.5^{\circ} \mathrm{E}$ & Historical WOUDC \\
Papeete & $18.0^{\circ} \mathrm{S}$ & $149.0^{\circ} \mathrm{W}$ & Historical WOUDC \\
& & & \& historical SHADOZ \\
La Reunion Island & $21.1^{\circ} \mathrm{S}$ & $55.5^{\circ} \mathrm{E}$ & Historical WOUDC \\
Ushuaia & $54.9^{\circ} \mathrm{S}$ & $68.3^{\circ} \mathrm{W}$ & Current WOUDC, GAW \\
Ascension Island & $8.0^{\circ} \mathrm{S}$ & $14.5^{\circ} \mathrm{W}$ & Historical WOUDC \\
& & & \& historical SHADOZ \\
\hline
\end{tabular}

Seidel and Free (2006) also found that increasing the uncertainty in temperature measurements has minor effects on the accuracy of the monthly means and standard deviations and is not an important factor in determining multi-decadal trends. The latter is consistent with our finding that the quality of the trend determination is compromised only when the measurement uncertainty exceeds $2 \mathrm{~K}$ and measurements are made just once or twice a month or less frequently. We find that, for a wide range of uncertainties and sampling frequencies, these aspects of a monitoring programme have little impact on the number of years required to detect the projected trend, which depends more on the natural variability and autocorrelation in the time series. As a result, at some locations such as in the tropics, the projected temperature trend is expected to be detected within 30 years or less, while for locations in the northern high latitudes, the projected trend will likely not be detected even within 100 years.

Given these constraints, we have endeavoured to find an objective selection process for the most suitable measurement sites where temperature trends in the mid-troposphere and lower stratosphere could be identified sooner than elsewhere. Note that this is just one example of an objective site selection strategy and that the resulting maps depend on the criteria used.

A similar technique was applied to find an optimal distribution of measurements sites to detect ozone trends in the shortest time possible. Since trends in total column ozone are not expected to be linear over the coming century over many regions of the globe, it is less pertinent to consider the time to detect expected 21 st century trends in total column ozone as an indicator of where total column ozone observing sites should be located. We have therefore investigated different time periods from 2010-2020 up to 2010-2050 to generate 31 sets of optimal sites for ozone trend detection, and the 10 measurement sites appearing most often within these 31 sets are listed in Table 5.

The objective method to determine optimal measurement sites presented here is based on an estimation of the geo- 
graphical distribution of the minimum time required to detect the projected trend. To estimate this quantity, we estimated the unforced variance in the signal and the degree of autocorrelation from historical data. The underlying assumption of our analysis is that climate change would not significantly affect these parameters. The minimum time to detect future trends also depends on the magnitude of the projected trends, which was estimated from chemistry-climate simulations. These models are the best tools we currently have to estimate future trends and have been shown to reasonably capture past trends in Southern Hemisphere stratospheric temperatures (Young et al., 2013). It should be noted, though, that there is a large uncertainty in current estimates of past stratospheric temperature trends (Thompson et al., 2012) which limits our ability to validate past temperature trends simulated by these models.

While our proposed method for future site selection only depends on the geographical distribution of the minimum time to detect the projected trend and the geographical distance between measurement sites for two selected pressure levels, other factors may be considered as well. For example, to be able to detect projected changes in the width of the tropics, it would be beneficial to select a station close to the boundary of the tropics (e.g. GRUAN-RP-4, 2014). Proximity to the source region of El Niño might be another consideration given that trends in this region will likely have global impacts. Finally, one might be interested in detecting changes in tropopause height, a factor not considered in our study.

Studies such as the one presented here provide a sound scientific basis for decision making with regard to new and existing measurements sites and can help reduce costs and concentrate efforts where they are the most needed and most effective.

Acknowledgements. This work was funded in part through the Support to Science Element ESA (European Space Agency) SPARC (Stratosphere-troposphere Processes And their Role in Climate) initiative (ESA contract no. 4000105291/12/I-NB), and we take this opportunity to acknowledge ESA for this support. Funding from the NOAA GCOS office, through the Meteorological Service of New Zealand Ltd, was also essential for completing this work. We would also like to thank Chi-Fan Shih from the National Center for Atmospheric Research in Boulder, CO, for providing the NCEP CFSR reanalyses. We acknowledge the Chemistry-Climate Model Validation (CCMVal) activity for providing model results from the REF-B2 reference simulations. We also thank the University of Alabama (UAH) and Remote Sensing Systems (RSS) for access to the MSU and AMSU temperature data. The authors wish to thank Anna Mikalsen for helpful comments on the manuscript.

Edited by: M. Dameris

\section{References}

Adams, C., Bourassa, A. E., Sofieva, V., Froidevaux, L., McLinden, C. A., Hubert, D., Lambert, J.-C., Sioris, C. E., and Degenstein, D. A.: Assessment of Odin-OSIRIS ozone measurements from 2001 to the present using MLS, GOMOS, and ozonesondes, Atmos. Meas. Tech., 7, 49-64, doi:10.5194/amt-7-49-2014, 2014.

Balis, D., Kroon, M., Koukouli, M. E., Brinksma, E. J., Labow, G., Veefkind, J. P., and McPeters, R. D.: Validation of Ozone Monitoring Instrument total ozone column measurements using Brewer and Dobson spectrophotometer groundbased observations, J. Geophys. Res., 112, D24S46, doi:10.1029/2007JD008796, 2007.

Bodeker, G. E., Boyd, I. S., and Matthews, W. A.: Trends and variability in vertical ozone and temperature profiles measured by ozonesondes at Lauder, New Zealand: 1986-1996, J. Geophys. Res., 103, 28661-28681, 1998.

Bodeker, G. E., Scott, J. C., Kreher, K., and McKenzie, R. L.: Global ozone trends in potential vorticity coordinates using TOMS and GOME intercompared against the Dobson network: 1978-1998, J. Geophys. Res., 106, 23029-23042, 2001.

Eyring, V., Cionni, I., Bodeker, G. E., Charlton-Perez, A. J., Kinnison, D. E., Scinocca, J. F., Waugh, D. W., Akiyoshi, H., Bekki, S., Chipperfield, M. P., Dameris, M., Dhomse, S., Frith, S. M., Garny, H., Gettelman, A., Kubin, A., Langematz, U., Mancini, E., Marchand, M., Nakamura, T., Oman, L. D., Pawson, S., Pitari, G., Plummer, D. A., Rozanov, E., Shepherd, T. G., Shibata, K., Tian, W., Braesicke, P., Hardiman, S. C., Lamarque, J. F., Morgenstern, O., Pyle, J. A., Smale, D., and Yamashita, Y.: Multimodel assessment of stratospheric ozone return dates and ozone recovery in CCMVal-2 models, Atmos. Chem. Phys., 10, 94519472, doi:10.5194/acp-10-9451-2010, 2010.

Free, M., Durre, I., Aguilar, E., Seidel, D., Peterson, T. C., Eskridge, R. E., Luers, J. K., Parker, D., Gordon, M., Lanzante, J., Klein, S., Christy, J., Schroeder, S., Soden, B., Mcmillan, L. M., and Weatherhead, E.: Creating climate reference datasets; CARDS Workshop on Adjusting Radiosonde Temperature Data for Climate Monitoring, B. Am. Meteorol. Soc., 83, 891-899, 2002.

GCOS-73: Guide to the GCOS surface and upper-air networks: GSN and GUAN (Version 1.1), WMO/TD No. 1106, 2002.

GRUAN-RP-4: Outcomes of the GRUAN Network Expansion Workshop, available at: www.gruan.org (last access: 3 November 2014), 2014.

Immler, F. J., Dykema, J., Gardiner, T., Whiteman, D. N., Thorne, P. W., and Vömel, H.: Reference Quality Upper-Air Measurements: guidance for developing GRUAN data products, Atmos. Meas. Tech., 3, 1217-1231, doi:10.5194/amt-3-1217-2010, 2010.

IPCC (Intergovernmental Panel on Climate Change): Special report on emissions scenarios: a special report of Working Group III of the Intergovernmental Panel on Climate Change, 599 pp., Cambridge University Press, Cambridge, UK, 2000.

Kistler, R., Kalnay, E., Collins, W., Saha, S., White, G., Woollen, J., Chelliah, M., Ebisuzaki, W., Kanamitsu, M., Kousky, V., van den Dool, H., Jenne, R., and Fiorino, M.: The NCEP-NCAR 50year reanalysis: Monthly means CD-ROM and documentation, B. Am. Meteorol. Soc., 82, 247-267, 2001.

Mears, C. A. and Wentz, F. J.: Construction of the Remote Sensing Systems V3.2 Atmospheric Temperature Records from the MSU and AMSU Microwave Sounders, J. Atmos. Ocean. Tech., 26, 1040-1056, 2008. 
Saha, S., Moorthi, S., Pan, H.-L., Wu, X., Wang, J., Nadiga, S., Tripp, P., Kistler, R., Woollen, J., Behringer, D., Liu, H., Stokes, D., Grumbine, R., Gayno, G., Wang, J., Hou, Y.-T., Chuang, H.Y., Juang, H.-M. H., Sela, J., Iredell, M., Treadon, R., Kleist, D., Van Delst, P., Keyser, D., Derber, J., Ek, M., Meng, J., Wei, H., Yang, R., Lord, S., van den Dool, H., Kumar, A., Wang, W., Long, C., Chelliah, M., Xue, Y., Huang, B., Schemm, J.-K., Ebisuzaki, W., Lin, R., Xie, P., Chen, M., Zhou, S., Higgins, W., Zou, C.-Z., Liu, Q., Chen, Y., Han, Y., Cucurull, L., Reynolds, R. W., Rutledge, G., and Goldberg, M.: The NCEP Climate Forecast System Reanalysis, B. Am. Meteorol. Soc., 91, 1015-1057, 2010.

Seidel, D. J. and Free, M.: Measurement Requirements for Climate Monitoring of Upper-Air Temperature Derived from Reanalysis Data, J. Climate, 19, 854-871, 2006.

Thompson, D. W. J., Seidel, D. J., Randel, W. J., Zou, C., Butler, A. H., Mears, C., Osso, A., Long, C., and Lin, R.: The mystery of recent stratospheric temperature trends, Nature, 491, 692-697, 2012.

Tiao, G. C., Reinsel, G. C., Xu, D., Pedrick, J. H., Zhu, X., Miller, A. J., DeLuisi, J. J., Mateer, C. L., and Wuebbles, D. J.: Effects of autocorrelation and temporal sampling schemes on estimates of trend and spatial correlation, J. Geophys. Res., 95, 20507-20517, 1990.

Tobin, D. C., Revercomb, H. E., Knuteson, R. O., Lesht, B. M., Strow, L. L., Hannon, S. E., Feltz, W. F., Moy, L. A., Fetzer, E. J., and Cress, T. S.: Atmospheric Radiation Measurement site atmospheric state best estimates for Atmospheric Infrared Sounder temperature and water vapor retrieval validation, J. Geophys. Res., 111, D09S14, doi:10.1029/2005JD006103, 2006.
Tummon, F., Hassler, B., Harris, N. R. P., Staehelin, J., Steinbrecht, W., Anderson, J., Bodeker, G. E., Bourassa, A., Davis, S. M., Degenstein, D., Frith, S. M., Froidevaux, L., Kyrölä, E., Laine, M., Long, C., Penckwitt, A. A., Sioris, C. E., Rosenlof, K. H., Roth, C., Wang, H.-J., and Wild, J.: Intercomparison of vertically resolved merged satellite ozone data sets: interannual variability and long-term trends, Atmos. Chem. Phys., 15, 3021-3043, doi:10.5194/acp-15-3021-2015, 2015.

Wang, J. S., Seidel, D. J., and Free, M.: How well do we know recent climate trends at the tropical tropopause?, J. Geophys. Res., 117, D09118, doi:10.1029/2012JD017444, 2012.

Weatherhead, E. C., Reinsel, G. C., Tiao, G. C., Jackman, C. H., Bishop, L., Hollandsworth Frith, S. M., DeLuisi, J., Keller, T., Oltmans, S. J., Fleming, E. L., Wuebbles, D. J., Kerr, J. B., Miller, A. J., Herman, J., McPeters, R., Nagatani, R. M., and Frederick, J. E.: Detecting the recovery of total column ozone, J. Geophys. Res., 105, 22201-22210, 2000.

Whiteman, D. N., Vermeesch, K. C., Oman, L. D., and Weatherhead, E. C.: The relative importance of random error and observation frequency in detecting trends in upper tropospheric water vapor, J. Geophys. Res., 116, D21118, doi:10.1029/2011JD016610, 2011.

WMO/UNEP (World Meteorological Organization/United Nations Environment Programme): Scientific Assessment of Ozone Depletion: 2006, Global Ozone Research and Monitoring Project Report No. 50, 572 pp., Geneva, Switzerland, 2007.

Young, P. J., Butler, A. H., Calvo, N., Haimberger, L., Kushner, P. J., Marsh, D. R., Randel, W. J., and Rosenlof, K. H.: Agreement in late twentieth century Southern Hemisphere stratospheric temperature trends in observations and CCMVal-2, CMIP3, and CMIP5 models, J. Geophys. Res.-Atmos., 118, 605-613, 2013. 